\title{
ENSINO-APRENDIZAGEM DE MATEMÁTICA: COM ENFOQUE NA AFETIVIDADE E NA CONTEXTUALIZAÇÃO NAS AÇÕES PEDAGÓGICAS
}

\section{ARTIGO ORIGINAL}

SORTE, Mágela Domingues Boa ${ }^{1}$

COÊLHO, Márcio Wendel Santana ${ }^{2}$

SORTE, Mágela Domingues Boa. COÊLHO, Márcio Wendel Santana. Ensinoaprendizagem de matemática: Com enfoque na afetividade e na contextualização nas ações pedagógicas. Revista Científica Multidisciplinar Núcleo do Conhecimento. Ano 04, Ed. 11, Vol. 05, pp. 174-189. Novembro de 2019. ISSN: 2448-0959, Link de

acesso: https://www.nucleodoconhecimento.com.br/educacao/enfoque-na-

afetividade

\section{RESUMO}

O presente artigo tem como finalidade analisar a relevância do afeto e como ele se manifesta no exercício pedagógico diário da docência nos processos de ensinoaprendizagem de Matemática e de que forma esses aspectos interferem na interação professor-aluno. É de suma importância compreender a amplitude da afetuosidade na construção das competências e habilidades básicas do sistema de aquisição do

\footnotetext{
${ }^{1}$ Mestrado em Ciências da Educação, Pós-graduação em Metodologia e Ensino e Pesquisa na educação em Matemática e Física, Docência Universitária, Gestão Escolar e Orientação Educacional e Especialista em Ciências da Educação e Graduação Licenciatura em Matemática.

2 Doutor em Ciências da Saúde \& Psicanálise Clínica e Doutor em Ciências da Educação, Mestre em Ciências da Educação, Especialista em: Pedagogia Escolar \& Psicologia Escolar e Graduado em Pedagogia.
} 
conhecimento. Portanto, na realização deste trabalho buscamos respaldo nas contribuições de autores basilares como Wallon, Piaget e Vygotsky. A referida pesquisa realizou-se baseada em estudo teórico e revisão bibliográfica visando adquirir conhecimentos concernentes à temática em foco. $\mathrm{O}$ estudo foi pautado no levantamento bibliográfico da seleção de livros e artigos científicos, além de páginas da Internet e sites relacionados ao tema. A fundamentação para este trabalho teve aporte teórico nos estudos de Wallon, em que traz como proposta, a significância da afetividade nos segmentos mentais que consiste a pessoa, Chacón que discorre a respeito do propósito das emoções na Educação Matemática, D’Ambrósio e Fazenda que discutem questões plausíveis acerca das relações que envolvem os processos de ensino-aprendizagem dos conhecimentos matemáticos bem como sobre as diretrizes que regem a educação brasileira, tais como: LDB - Lei de Diretrizes e Bases, PCN - Parâmetros Curriculares Nacionais e DCNEM - Diretrizes Curriculares Nacionais para o Ensino Médio, dentre outros.

Palavras-chave: Ensino-aprendizagem de Matemática, Afetividade, Contextualização.

\section{INTRODUÇÃO}

Discorrer sobre o que é o afeto implica-se na necessidade de refletir sobre como ele se manifesta. De certo modo é uma demonstração de sentir afeto e de afetado por algo ou alguém. Afeto é um substantivo abstrato que tem um sentido bastante relevante nas inter-relações humanas, tendo em vista que, estas são necessárias para uma convivência harmoniosa. Não apenas para pelejarmos com nossos sentimentos, mas também, para estipularmos conexões humanitárias efetivas. Em todo modelo de sociedade se faz necessário a busca por comportamentos mais humanos. Vivemos em uma sociedade onde presenciamos com muita frequência de sentimentos como egoísmo, tristeza, medo, apatia, aversão, violência, intolerância e etc., e isso aparenta nos dominar. Entender que uma discussão em prol da relevância da afetividade nas inter-relações pessoais é de suma importância nos dias atuais e também, um compromisso de todos, principalmente no setor educacional em que as interações humanas dependem da ligação entre sentimentos, respeito e responsabilidade. 
Não devemos negar o respeito às emoções dos outros, sem nos eximir da nossa contribuição, do altruísmo e da empatia; atitudes e comportamentos tão necessários para as demandas morais e sociais que nossa realidade carece. Partindo desse contexto, o referido estudo tem como finalidade refletir sobre a relevância do afeto nas relações que se constroem nos processos de ensino-aprendizagem bem como analisar o quanto ela ou a falta dela interfere nesse processo. A afetividade entre professor-aluno e aluno-aluno, não deve se limitar apenas no contato físico, levando em consideração que, essas trocas afetivas progridem ao respeito, à compreensão e ao diálogo, cabendo ao professor oferecer ao aluno oportunidades na realização das atividades, conforme as suas possibilidades e confiança. Devemos levar em conta que o estudante não deve ser considerado como uma caixa vazia a ser preenchida com exercícios repetitivos, mas sim, como protagonista que participa na construção e na aquisição dos seus conhecimentos.

Com isso, um relacionamento afetivo e harmonioso deve ser um grande desafio para o educador da atualidade. Com base nessa premissa, buscamos investigar como a relação afetiva interpessoal e práticas desafiadoras influenciam positiva ou negativamente na aprendizagem, bem como, interferem ou não, na metodologia de ensino. Neste sentido, para o referido trabalho foi realizado estudo teórico e revisão bibliográfica, visando adquirir conhecimentos acerca da temática em voga. Para o levantamento bibliográfico foram selecionados livros e artigos científicos, além de páginas da Internet em sites relacionados ao tema.

\section{FATOR EMOCIONAL E EDUCAÇÃO MATEMÁTICA: INTERFACES}

Recentemente o aspecto afetividade vem ganhando espaço no campo da Educação Matemática, sendo realizados inúmeros trabalhos nesta perspectiva. Pesquisas neste campo buscam compreender os efeitos da inter-relação professor e aluno e também os efeitos das manifestações relativas às emoções e aos sentimentos gerados nos estudantes nas diferentes situações apresentadas no espaço de convívio e trocas. Alguns autores dissertam a importância das emoções na aquisição dos conhecimentos de matemática e, dentre eles, o mais importante foi McLeod (1985, 1988, 1989, 1990). McLeod focou seus esforços na revisão bibliográfica acerca das 
emoções e do ensino da matemática, objetivando configurar um marco teórico para o afeto no estudo dos conceitos matemáticos. Tais pesquisas investigaram quais sentimentos eram provocados nos alunos quando estes se deparavam com a resolução de problemas, tanto quando conseguiam resolvê-los e quando nas situações de fracasso frente a eles.

McLeod investigou a interação cognição e também, as diferenças entre as reações emocionais de especialistas e iniciantes em Matemática. Mais recentemente, pesquisadores como DeBeliis \& Goldin, 1991; Bishop, 1999; Adams, 1989; Goméz e Chácon, 2003; dentre outros passaram a estudar o assunto. Em seu livro denominado Matemática Emocional, Chácon (2003), discorre sobre as pesquisas dos autores supracitados e descreve brevemente o objetivo dos mesmos. Ainda neste livro, Chácon explica que a resolução de problemas produz diferentes sentimentos nos alunos e aborda as emoções provocadas nos mesmos ao estabelecerem conexão com o professor de Matemática. Segundo Chacón (2003, p. 20): "Os indivíduos são constituídos a partir de manifestações que são compreendidas pelo domínio afetivo.

O domínio afetivo abrange comportamentos como: atitudes, crenças, considerações, gostos e preferências, emoções, sentimentos e valores" e essas manifestações variam de pessoas para pessoas. Para melhor entendimento dos termos supracitados e compreender a relação destes com a Educação matemática, defini-lo-emos basicamente, conforme os estudos de Chacón, uma vez que, esta área é carente de referências bibliográficas. Segundo Chacón (2003), crenças são tudo aquilo que o indivíduo tem como verdade, as quais foram oriundas de suas concepções e vivências. Na versão de McLeod, citado por Chácon:

Podem ser classificadas em termos do objeto de crença: crenças sobre a Matemática (o objeto); sobre si mesmo; sobre o ensino da Matemática e crenças sobre o contexto no qual a Educação Matemática acontece (contexto social) (MCLEOD, 1992 apud GÓMEZ CHACON, 2003, p. 20).

Partindo dessa premissa, as crendices sobre os aspectos que giram em torno da Educação Matemática podem gerar o prejulgamento sobre a sua aprendizagem, acarretando, muitas vezes, danos irreparáveis para o sistema educacional. O 
preconceito de que para aprender Matemática o indivíduo tem que ter uma mente privilegiada e que esse fenômeno é um privilégio para poucos, pode gerar um incômodo nós não "privilegiados", causando com isso, a apatia e o distanciamento sucessivo do estudante frente à Matemática. Nesses termos, Chacón (2003) suscita que as crenças acima citadas são fatores essenciais para o êxito na aprendizagem matemática, pois estas podem motivar ou desmotivar os alunos. Ademais, a metodologia utilizada pelo professor também deve condizer com as perspectivas dos alunos, uma vez que estes podem reconhecer a Matemática como uma ciência possível de se entender, e também, presente na sua vida cotidiana.

A maioria dos estudantes acredita que os problemas matemáticos só podem ser solucionados mediante regras, fórmulas e/ou métodos fornecidos pelo professor. São estimulados a utilizar regras e macetes/atalhos, investindo mais tempo em calcular/repetir/treinar os exercícios de fixação do conhecimento, do que em refletir, de fato, sobre a interpretação do problema. Muitas vezes, conseguem resolver o problema proposto, mas quando chegam à solução indicada tem certeza de que a mesma está correta, contudo, não sabem o seu significado e aplicação. Dessa forma, passam a enxergar a matemática ensinada na escola como uma ciência difícil de ser compreendida e inútil, pois não conseguem estabelecer uma ligação entre ensino e vivência. Dessa forma, muitos alunos desenvolvem a crença de que a Matemática tem um alto grau de abstração e de difícil entendimento.

Referente às crenças que os estudantes têm si mesmos e das crenças que os educadores têm dos estudantes, constitui na percepção que cada indivíduo possui sobre si e, como o aprendiz de matemática e a estrutura do autoconceito estão relacionadas às suas perspectivas e sua identidade social. Para Chacón, esta crença:

(...) está relacionada as atitudes, a perspectiva do mundo matemático e com a identidade social. $O$ autoconceito em relação a matemática é formado por conhecimentos subjetivos (crenças, cognições), as emoções e as intenções de ação sobre si mesmo referentes a matemática (CHACÓN, 2003, p. 75). 
Nesses termos observamos que essas crenças são referentes ao autoconceito, à confiança e à atribuição das causas do sucesso ou do fracasso na Educação Matemática. Ainda para a autora,

(...) as crenças que os jovens manifestam sobre o sucesso e o fracasso em matemática envolvem valores do grupo social, de sua dimensão afetiva e do posicionamento que elas assumem diante da matemática. O gosto pela matemática aparece como um motivo interno incontrolável (CHACÓN, 2003, p. 77).

Percebemos com isso que, a emoção é uma demonstração que se apresenta de diferentes maneiras, podendo ser de diversos sentimentos como felicidade, infelicidade, alegria, desânimo, entusiasmo, etc. Os atos emocionais são os resultados das crenças adquiridas através das experiências de vida, seja no contexto cultural ou social. As manifestações de sentimentos bons ou ruins que os alunos estabelecem com a matemática podem ter origem nas suas crenças ou mesmo nas suas experiências com as pessoas envolvidas no processo educacional. Conforme Chacón (2003) existem emoções favoráveis e desfavoráveis nas técnicas de aprendizagem. Essas emoções podem ter grande influência na aquisição dos conhecimentos pelos alunos e estas podem gerar satisfação ou frustração. Dentre as emoções favoráveis à aprendizagem, podemos mencionar a sensação de contentamento, de prazer e da curiosidade em aprender, etc.

Concluímos como isso que, as reações emocionais de satisfação são manifestadas quando os alunos conseguem realizar as tarefas propostas com facilidade e sentem que progrediram. Em contra partida, as reações de frustração são observadas quando os alunos se sentem bloqueados e incapazes de resolverem as atividades propostas, ou seja, são tomados pela sensação de fracasso. É perceptível quando os alunos deparam com experiências frustrantes na resolução de problemas. Eles passam a apresentar dificuldade em controlar suas emoções. Portanto, o descontrole dessas emoções pode ser contornado mediante intervenção. Contornável quando compreender que, na resolução de problemas pode haver interrupções e bloqueios, e que, caso haja frustração, deve encará-la como um aspecto indissociável 
do processo. Isso implica na necessidade de que ela reaja, insista na busca da solução e evite que as reações emocionais se tornem negativas.

Manifestações como o medo, a incerteza e a falta de confiança fazem parte das emoções desfavoráveis a aprendizagem. As quais, muitas vezes, causam frustração, desânimo e aborrecimentos aos alunos, fazendo com que estes se desinteressem e se afastem da continuidade de algumas atividades. Segundo Chacón (2003), as emoções são essenciais na interação social no instante que se estabelecem relações de pertencimento a um grupo ou sociedade. Os estados de ânimo como afeto, humor, alegria, medo, apatia, etc. são as emoções que acompanham e derivam ou antecipam a avaliação que a pessoa faz de suas transações no convívio social. Entretanto, vale ressaltar que a concepção de emoção utilizada pela perspectiva histórico-cultural não é a mesma utilizada na esfera da educação matemática. Mesmo porque a diferença entre emoção, sentimentos e paixão não se aplica nos estudos de matemática emocional.

Emoção e sentimentos são tratados como sinônimos, representando os estados subjetivos do indivíduo. Além disso, enquanto a Educação Matemática volta-se para aspectos específicos do ensino-aprendizagem dos conteúdos desta área do conhecimento, os valores que os discentes possuem relacionados aos conhecimentos matemáticos, dentre outros. Dessa forma, perspectiva histórico-cultural enfatiza o impacto da mediação pedagógica nas relações estabelecidas objeto e sujeito, supondo que estas relações são também de cunho afetivo. Com isso, percebemos que os estudos realizados em torno da afetividade, dentro da perspectiva da educação matemática, centram-se nas reações dos alunos, sejam especialistas ou iniciantes. Ademais, buscar compreender o que as práticas pedagógicas concretas e desenvolvidas pelo professor, provocam nos estudantes é fundamentado na perspectiva histórico-cultural. Mais especificamente, se os fazem sentirem-se atraídos ou não pelo conhecimento. 


\section{A LEGISLAÇÃO DA EDUCAÇÃO MATEMÁTICA NO BRASIL}

É indiscutível que os conhecimentos sistematizados se configuram como elementos fundamentais que orientam a vida humana e as suas dimensões pessoal e profissional. É algo inerente a todos os cidadãos, e, dessa forma, é um direito que deve ser gozado por todos. Assim, é papel do ambiente escolar viabilizar e guiar todos na busca pela aquisição de múltiplos saberes. Sabe-se que existem elementos que enfatizam aproximações e distanciamentos quando se fala sobre as políticas educacionais que orientam o Ensino Médio brasileiro, sobretudo em relação às ideias voltadas à formação tecnológica e integrada. Essas ideias se firmaram em três momentos. O primeiro deles se trata da elaboração da LDB; das Diretrizes Curriculares para o Ensino Médio, do ano de 1998 (Parecer CNE/CED 15/98) e da concretização da Educação Profissional de 1999 (Parecer CNE/CEB 16-99).

O segundo momento, por sua vez, compreende as Diretrizes Curriculares Nacionais para o Ensino Médio em voga (Parecer CNE/CEB 05/2011) e a Resolução CNE/CEB (02/2012). O terceiro momento, por fim, diz respeito à Educação Profissional Técnica de Nível Médio (Parecer CNE/CEB 11/2012) e à Resolução CNE/CEB (06/2012). A importância dessa discussão se fundamenta, principalmente, nas limitações relacionadas tanto à ampliação quanto ao aperfeiçoamento das ideias que norteiam o Documento Referencial para a realização da Conferência Nacional de Educação (CONAE, 2014).

Pretende-se, também, analisar as possibilidades decorrentes da Conferência, uma vez que orienta e subsidia as políticas que orientam a educação brasileira para o Ensino Médio, tema dessa pesquisa. Sobre o ensino de Matemática institucional, os PCN são documentos que auxiliam no exercício da docência bem como atuam como ferramentas que proporcionam o surgimento de novos estudos, reflexões, discussões, teorias e afins visando apresentar uma proposta curricular norteadora assim como proporciona aos professores informações pertinentes, BRASIL (2001). Consta nos PCN: 
A matemática precisa estar ao alcance de todos e a democratização do seu ensino deve ser meta prioritária do trabalho docente. - No ensino de Matemática, destacam-se dois aspectos básicos: um consiste em relacionar observações do mundo real com representações; outro consiste em relacionar essas representações com princípios e conceitos matemáticos (BRASIL, 1997, p.19).

Concomitantemente, os PCN também pontuam não haver apenas um único caminho para o aprendizado da Matemática. Destacam metodologias a serem aplicadas no ambiente escolar: evidencia a ligação do aprendiz com a causa de estudo, igualmente a sua participação na consolidação do seu aprendizado, deixando de ser um sujeito passivo para se tornar um sujeito participativo na construção do seu conhecimento. A LDB - Lei de Diretrizes e Bases para a Educação, 9394/96 ou LDB/96. A referida visa a realização de uma reforma profunda no ambiente educacional do Brasil. Tal reformulação voltada ao Ensino Médio atua a partir de três objetivos norteadores: visa ampliar a oferta de vagas aos discentes; o investimento no aperfeiçoamento da docência bem como uma replanejamento do currículo em nível médio.

Outro documento importante produzido com essa finalidade são os Parâmetros Curriculares Nacionais (PCN) e as Orientações Curriculares Nacionais para o Ensino Médio (OCNEM). Ambas são documentos publicadas pelo Ministério da Educação e Cultura (MEC). O MEC ao elaborar tais documentos tinha como escopo fazer com que tais aparatos sirvam como materiais auxiliares para o professor da educação básica a fim de que esses tornem viável a reforma defendida pela LDB/96. Apesar da distribuição gratuita desses materiais na escola pública, verificou-se que os docentes da educação básica sabiam da existência do documento, contudo, não seguiam os PCNEM no exercício docente diário. Assim sendo, o MEC, no ano de 2004, incitou a discussão da temática no âmbito nacional. A discussão foi feita com discentes e docentes do Ensino Médio bem como com sociedades científicas e com Secretarias Estaduais da Educação.

A partir dessas reflexões na esfera nacional, o MEC realizou uma terceira atualização nesses documentos para que os parâmetros anteriores fossem substituídos com base nas discussões recentes. Caminhando para o ano de 2006, o mesmo órgão elaborou e publicou as Orientações Curriculares para o Ensino Médio. O documento reitera que 
é responsabilidade dos professores de Ensino Médio formar cidadãos que possam atuar de forma ética, autônoma e responsável. Esses devem ser capazes, também, de compreender como os processos nas diversas áreas do conhecimento são construídos. Destarte, esses alunos, ao concluírem o nível médio, devem estar aptos para atuar no mercado de trabalho preservando esses ideais construídos no Ensino Médio. Ao refletir sobre o papel da Matemática neste contexto, deve-se pensar em como ela deve colaborar com esse processo formativo do aluno.

Ao discorrer sobre a responsabilidade da Matemática nesse processo formativo é preciso destacar que é inadmissível que ela seja apresentada e ensinada de forma fragmentada, descontextualizada, repetitiva e sem considerar a realidade tanto da escola quanto e principalmente dos alunos. Nesse sentido, a disciplina deve contribuir para que os alunos sejam capazes de refletir, pensar e analisar situações diversas, criadas a partir de sua realidade, para resolver problemas do cotidiano. Deve, ainda, haver um envolvimento dos discentes e docentes com o contexto social, cultural e econômico que os circunda. É preciso que haja uma ampliação da visão de mundo que se tem dessa realidade a partir do ensino da Matemática. As Orientações Curriculares para o Ensino Médio reiteram que:

Espera-se que os alunos saibam usar a Matemática para resolver problemas práticos do quotidiano; para modelar fenômenos em outras áreas do conhecimento; compreendam que a Matemática é uma ciência com características próprias, que se organiza via teoremas e demonstrações; percebem a Matemática como um conhecimento social e historicamente construído; saibam apreciar o valor da Matemática no desenvolvimento científico e tecnológico. (BRASIL, 2006, p.69).

Conforme apresentado, as instituições pertencentes à esfera da educação têm uma responsabilidade intransferível: devem proporcionar condições favoráveis para que os alunos possam desenvolver habilidades e competências de forma multidisciplinar. Para tanto, é fundamental que sejam instigados a compreender como a sociedade é complexa, competitiva e carente de valores morais e éticos bem como de cidadãos críticos, reflexivos e conscientes. Nesse contexto, a relevância dos conhecimentos matemáticos é a oferta dessa disciplina de conceitos científicos que orientaram e orientam até hoje a sociedade. São eles que fazem com que a sociedade evolua. Os 
alunos devem compreender, também, que o conhecimento é indispensável para que se possa viver nesse mundo que, a cada dia, torna-se mais tecnológico e competitivo. Para D'Ambrosio (2001) o ensino atual da Matemática não viabiliza que os estudantes estejam preparados para lidar com os desafios com os quais se deparam hoje,

(...) a matemática e a educação matemática não podem ser insensíveis aos problemas maiores que afeta o mundo moderno, principalmente a exclusão de indivíduos, comunidades, e até nações, dos benefícios da modernidade. A matemática é o maior fator de exclusão nos sistemas escolares. O número de reprovações e evasões é intolerável. (D'AMBROSIO, 2001, p. 16)

Frente a isso, de tempos em tempos, são apresentadas sugestões de novas metodologias e mudanças curriculares, em busca da promoção e melhoramento do desempenho na Educação Matemática da Educação Básica. No último nível da educação básica, espera-se que o ensino da disciplina aqui apresentada seja capaz de enfatizar, com mais afinco, a formação humana em dimensões diversas. Tal ideal é amparado pelos documentos oficiais. Os objetivos neste último nível são: ajudar na capacidade de relacionar as ideias e o raciocínio lógico e dedutivo e visa, também, apresentar a função instrumental, sendo esta uma ferramenta que serve tanto para a vida cotidiana como também para tarefas específicas em muitas atividades humanas, pois esta é um instrumento que norteia a construção do conhecimento e lhe atribui o caráter de precisão na formação dos sujeitos.

Nesses termos, o valor formativo da Matemática visa contribui para a formação de concepções e da aquisição de atitudes, cuja utilidade supera o âmbito do campo matemático, possibilitando ao educando a capacidade para resolver problemas exatos de forma multidisciplinar, ampla e dinâmica, produzindo, dessa forma, hábitos de investigação, o que constrói, nesses alunos, sentimentos positivos, como, por exemplo, o da confiança e o da motivação para aceitar e enfrentar situações que antes ao menos considerariam. Essa abordagem enfatiza, ainda, o alargamento de interpretações científicas e múltiplas sobre os problemas do mundo real (BRASIL, 2006). Portanto, é crucial que sejam elaborados instrumentos capazes de colocar em prática estratégias que viabilizam o desenvolvimento das competências e habilidades diversas a partir de exercícios que permitem a mobilização e construção de 
conhecimentos matemáticos inter-relacionados de forma múltipla. D'Ambrosio (2001), em seu estudo, afirma que o maior desafio é a união dos conhecimentos matemáticos ao mundo real. Alerta, também, que essa dissociação é bastante perigosa.

As Diretrizes Curriculares, para ele, reiteram que a Matemática ficou, durante muito tempo, atrelada às Ciências da Natureza, e, assim, "retirar a Matemática do isolamento didático em que tradicionalmente se confina na conjuntura escolar" (BRASIL, 1998). Provavelmente essa visão discriminada sobre a disciplina aqui tomou forma devido ao fato de que a educação, historicamente, configurou-se dessa forma. Algumas possibilidades pedagógicas e metodológicas são apontadas nos documentos oficiais no sentido de promover o desenvolvimento das habilidades e competências básicas dos estudantes. O ensino da Matemática no Ensino Médio deve ser atrativo e relacionado aos problemas reais. Para que esse desafio seja concretizado se faz necessário investigar os meios de aquisição do conhecimento matemático nessa modalidade de ensino, auxiliando o repensar do currículo de Matemática e, mais ainda, no alicerçamento da identidade dessa modalidade de ensino.

\section{O ENSINO E A APRENDIZAGEM DE MATEMÁtICA NUMA PERSPECTIVA CONTEXTUALIZADA E AFETIVA}

Não é difícil concordar com as críticas feitas à educação na atualidade. É perceptível o baixo índice de aprendizado desempenhado pelos alunos ao chegarem à etapa final da educação básica, ou seja, ainda não atinge a todos. As comprovações são inúmeras: basta analisar o desempenho dos alunos no ENEM, no SAEEB, no Relatório Pisa, na Olimpíada de Matemática, etc. Inúmeros artigos, de acordo a LDB, relatam a finalidade da educação básica, natureza tríplice natureza, sendo elas: o pleno desenvolvimento do educando, o preparo para exercício da cidadania e a qualificação. Percebe-se, então, que a educação não se trata, apenas, do repasse de dados e fatos. É preciso que o processo educativo construa, ou seja, forme, de fato, os alunos para atuarem como cidadãos. Assim, é de extrema importância uma prática pedagógica atrelada à afetividade e à contextualização. 
O conhecimento não deve enfatizar, apenas, a racionalidade. É preciso que todas as dimensões humanas sejam trazidas para o ambiente da educação. Assim, o ato de educar implica na adesão de uma visão plural e dinâmica sobre os múltiplos saberes, ou seja, deve compreender áreas do conhecimento de forma multidisciplinar. Para isso, os domínios afetivo, racional e transcendental devem ser reiterados sem hierarquia (MORAN, 1993). O ensino-aprendizagem deve estar aberto a novas experiências para que os alunos encontrem sentido naquilo que lhes é apresentado. Vem daí a pluralidade do conhecimento. É algo bastante complexo para os professores de Matemática, uma vez que há certa tendência a apresentar os conhecimentos matemáticos de forma descontextualizada e pouco acessível, o que gera o desinteresse.

As boas relações no cotidiano escolar podem enfatizar a afetividade aqui buscada. Tais relações possibilitam que os conhecimentos matemáticos sejam aprendidos de forma mais prazerosa e eficaz. Para tanto, aderir a uma prática educativa que enfatiza diferentes níveis, significados e significantes é essencial. $O$ ato de ensinar deve, portanto, unir realidades distintas para que haja uma troca múltipla de experiências. Assim, torna-se um desafio o esforço para compreender essas realidades múltiplas a partir de competências e habilidades diversas. Elas são, cada uma a sua forma, indispensáveis para que boas relações sejam mantidas no convívio em grupos. Não se trata, apenas, de aprender a lidar melhor com os sentimentos. Implica-se, também, na necessidade de construir e manter relações humanas não superficiais, mas sim especiais e significativas.

A afetividade ganha um papel sumário neste processo. Trata-se do emprego de emoções que nós mesmos aprendemos e cultivamos ao nos relacionarmos com os grupos mais distintos, desde a família até os nossos amigos, colegas de trabalho, etc. São inerentes à todo e qualquer ser humano. Nesses termos, a proposta sobre afetividade de Wallon (1879 -1962) aborda como proposta, a importância da afetividade para a evolução das estruturas mentais que consistem na pessoa. Fundamenta-se na visão não fragmentada da formação humana, buscando compreendê-lo na óptica do desenvolvimento motor, do comportamento humano, das 
alterações que ocorrem no transcorrer da nossa vida, desde a infância até o envelhecimento, desde os processos voltados à afetividade e à inteligência até as conexões que a pessoa estabelece no meio em que vive a partir de suas interações (ARANTES, 2003).

Wallon, em seu estudo, alude que pretende ultrapassar as visões que assimilavam as emoções como acompanhamento da ação humana ou membro que, de alguma forma, a perturba. O autor, para elaborar a sua reflexão, volta-se ao princípio da vida, indicando que, sendo esse o momento que as emoções têm maior presença, talvez seja esta a fonte de sua compreensão. Admitindo que são sintomas difíceis e instáveis, seus resultados apontam que para que se adira a uma outra postura, é preciso superar uma tendência mecanicista para aderir a um pensamento mais dialético. Com tal substituição de postura, visa compreender como as oposições diversas se manifestam no mundo real. Para tanto, busca analisar a relação entre os agentes orgânicos e sociais bem como se atenta as contestações e as interdependências existentes entre os outros campos funcionais e a emoção, fatores que evidenciam no desenvolvimento da pessoa.

Para Piaget, Souza (apud ARANTES, 2003), a afetividade além das emoções e dos sentimentos, implica, ainda, nas tendências e nas vontades. Por funções afetivas entende que essas de forma ampla. Como exemplo menciona a percepção. Quando se refere a ela pensa em sua natureza, essencialmente, seletiva, em razão do afeto. Assim sendo, Wallon, quando elucida sobre as emoções primárias, em seu estudo sobre o recém-nascido, entende que tais sentimentos se relacionam com uma sensação proprioceptiva. Cita, como exemplo, a perda do equilíbrio. Para Wallon, com tal perda, há um fator perceptivo que se manifesta já nas emoções primárias. Todavia, em relação aos sentimentos que chama de "mais evoluídos", entende que estão ligados ao campo cognitivo. Vygotsky, por sua vez, compreende, em suas reflexões, que o desenvolvimento individual-pessoal se manifesta em dois níveis.

O primeiro deles seria o proximal ou potencial (referente às habilidades a serem construídas) e o real ou efetivo (que diz respeito às conquistas realizadas). Devido ao fato que se preocupou, primeiramente, com os elementos ligados ao funcionamento 
do pensamento humano, Vygotsky é considerado, por autores e pesquisas distintas, como cognitivista. Contudo, o autor questionava, em suas reflexões, o contraste entre as esferas afetiva e cognitiva, sobretudo quando defende que a Psicologia tradicional deixa a desejar quando separa os elementos intelectuais dos afetivos-volitivos. Ele enfatiza que "os processos pelos quais o afeto e o intelecto se desenvolvem estão inteiramente enraizados em suas inter-relações e influências mútuas".

Com isso, visa unir a perspectiva afetiva e cognitiva, de forma que as emoções tenham um espaço significativo, que possam facilitar ou dificultar a aprendizagem, sendo uma necessidade de mudança na relação afetiva na prática de ensinar e aprender, pois conforme Chacón (2003). "o ensinar e o aprender não acontecem em um âmbito isolado e neutro, mas dependem do contexto no qual se ensina e do comportamento humano dos participantes". Assim, ao se propor um projeto na escola, tendo como objetivo, integrar o aluno na assimilação do conhecimento, não o faça verificar informações e aplicá-las diretamente ao projeto, pois para concretizar essa ligação, o aluno tem que desenvolver capacidades próprias do conhecimento, que the possibilitará trabalhar em projetos coletivos e individuais. Portanto é chegada a hora de ré-encantar a educação através da afetividade, da contextualização e das relações harmônicas, possibilitando ao estudante a dignidade, o exercício da sua cidadania e que seja capaz de aprender sempre e melhor. Enfatizar as potencialidades do aluno é responsabilidade da escola, e, sobretudo, do docente.

\section{CONSIDERAÇÕES FINAIS}

Atualmente a docência é compreendida como uma ação complicada de se entender exige dos professores muitas competências e habilidades, tais como: domínio do conteúdo relacionado; capacidade para motivar e instigar os discentes; consideração das dificuldades no desenvolvimento cognitivo; metodologias de trabalho prazerosas e desafiadoras, a exemplo do estímulo do trabalho coletivo objetivando trocas recíprocas na resolução de situações; ênfase no diálogo valorizado por ambas as partes e respeito as diferenças, defendendo, para isso, a pluralidade cultural de forma ampla, dentre outros aspectos. Nesses termos, o presente estudo nos possibilita resumir que a afetividade e a contextualização têm função essencial para atrair e 
despertar a atenção dos estudantes acerca dos conteúdos curriculares, principalmente da Matemática, dos professores que as ministram e, consequentemente, da aprendizagem escolar.

Contudo, os temas afetividade e contextualização ainda são estigmatizados ou ignorados na educação básica e nos programas voltados ao aperfeiçoamento de professores nas universidades, o que parece estranho, pois o ensino é uma atividade que envolve relações interpessoais, ou deveria ser. Dessa forma, as interações sujeito-objeto precisam ser agradáveis e significativas. Partindo desse princípio, a afetividade funciona como fator determinante para o êxito nas interações pessoais, tendo em vista que, para atribuirmos sentido àquilo que queremos aprender, se faz necessário que vejamos interesse naquilo que buscamos aprender, que criemos uma conexão afetiva com a finalidade desejada. Não seria exagero acreditar que através de uma relação afetiva positiva podemos conquistar e transmitir não só conhecimentos, como também, possibilitar o desenvolvimento de outras competências e habilidades necessárias para as inter-relações humanas positivas.

A partir de ações afetuosas podemos nos tornar docentes mais atentos, abertos e capacitados para a aquisição de novos conhecimentos e também para a experimentação de novas experiências. Vale ressaltar que, na educação e orientação escolar, a relação aluno e objeto de estudo mudam para melhor durante e depois do período de escolarização. Outro aspecto a ser beneficiado mediante as relações afetivas bem-sucedidas é a elevação da autoestima. É perceptível que o valor do amor-próprio elevado ou não, ou seja, autoestima e baixo autoestima é reflexo das relações de frustrações ou satisfações estabelecidas entre os indivíduos e as intenções e, na educação, entre o mediador e os indivíduos mediados. No exercício docente diário, o afeto e a união da teoria com a prática não devem ser dissociados. Esse processo deve está centrado na reflexão e no pensar.

Pensar nas condições de ensino, no que ensinar e como ensinar, em sua relevância, na união dos objetivos e com atividades capazes de estreitar os laços entre docente e discente, no que e como avaliar, na didática e metodologia de ensino são reflexões indispensáveis. A inter-relação quando pautada em práticas afetivas e 
contextualizadas direciona a uma aquisição cognitiva mais efetiva, pois facilita as relações e as ações pedagógicas. Dessa forma, reflete de forma positiva, influencia efetivamente nos processos cognitivos, na relação das vivências e na convivência professor/aluno, eleva a autoestima, validando a influência na relação aluno/conceitos a serem apreendidos. Acreditamos ser importante a reflexão das causas do fracasso escolar em Matemática e não apenas apontar os culpados, mas, também responsabilizar-se.

Nesse caso, a chamada à responsabilidade quer dizer, investigar as causas e investigar por possíveis soluções para a sanção dos mais diversos problemas. Um caminho na busca da solução dos problemas que emperram o êxito no ensinoaprendizagem de Matemática, talvez seja compreender como ocorre o conhecimento e os fatores que interferem no aprendizado e as diferentes teorias que podem transformar o trabalho pedagógico diário, levando-o a percorrer o caminho açãoreflexão-ação. É pertinente também, nessa pesquisa, recomendar a formação continuada do professor, da mesma maneira, a busca permanente do bemestar nos envolvidos no processo educacional, de forma que possamos reflitir sobre os componentes curriculares que estão sendo ofertados e a compatibilidade desta com as dimensões cognitiva, afetiva e social dos nossos alunos

\section{REFERÊNCIAS}

ARANTES, Valéria Amorim. Afetividade na escola: alternativas teóricas e práticas. In: SOUZA, Maria Thereza Costa Coelho. $O$ desenvolvimento afetivo segundo Piaget. São Paulo: Summus Editorial, 2003. p. 35-52.

BRASIL. Lei de Diretrizes e Bases da Educação Nacional. Lei número 9394, 20 de dezembro de 1996.

MEC. Conselho Nacional de Educação. Diretrizes Curriculares Nacionais

para o Ensino Médio. Proposta de Debate ao Parecer. Novembro, 2010b. 
Ciências da Natureza, Matemática e suas Tecnologias. Secretaria de Educação Básica. Brasília: Ministério da Educação, Secretaria de Educação Básica (Orientações Curriculares para o Ensino Médio; volume 2), 135 p. 2006.

. Diretrizes Curriculares Nacionais para o Ensino Médio: Diretrizes Curriculares Nacionais para o Ensino Médio. Parecer: CEB 15/98, Junho, 1998.

. Conselho Nacional de Educação. Resolução CNE/CEB no 3, de 26 de junho de 1998. Institui as Diretrizes Curriculares Nacionais para o Ensino Médio. Brasília: 1998. Disponível em: http://portal.mec.gov.br/ cne/arquivos/pdf/rceb03_98.pdf . Acesso em: 25 out. 2018.

. Conselho Nacional de Educação. Resolução CNE/CEB no 4, de 8 de dezembro de 1999. Institui as Diretrizes Curriculares Nacionais para a Educação Profissional. Brasília, 1999. Disponível em: http://portal.mec. gov.br/dmdocuments/rceb004_99.pdf. Acesso em: 29 set. 2018.

. Ministério da Educação. Parâmetros Curriculares Nacionais para o Ensino Médio. Brasília: MEC, 2000.

D’AMBRÓSIO, Ubiratan. Educação Matemática: da teoria à prática. Campinas, Papirus, 2001 (Coleção Perspectiva em Educação Matemática).

GOMÉZ CHACÓN, Inés Mํ. Matemática emocional: os afetos na aprendizagem matemática. Trad. Daisy Vaz de Moraes. Porto Alegre: Artmed, 2003.

LEITE, Sergio Antônio da Silva; TASSONI, Elvira Cristina Martins. A afetividade em sala de aula: as condições de ensino e a mediação do professor. In: AZZI, Roberta Gurgel; SADALLA, Ana Maria Falcão de Aragão (Org.). Psicologia e Formação docente: desafios e conversas. São Paulo: Casa do Psicólogo, 2002. p. 113 -14.

MCLEOD, D. B. Affective issues in research on teaching mathematical problem solving. In: E.A. Silver (Ead), Teaching and learning mathematical problem solving: 
multiple research perspectives. Hillsdale: Lawrence Erlbaum Associates, 1985, p. $267-$ 279.

MORAN COSTAS, José Manuel; MORAN, J. M. Leituras dos Meios de Comunicação. São Paulo: Pancast Editora, 1993.

VYGOTSKY, L. S.et al. A formação social da mente: o desenvolvimento dos processos psicológicos superiores. 6. Ed. São Paulo: Martins Fontes, 2003.

Psicologia Pedagógica. Martins Fontes: São Paulo, 2004.

WALLON, H. A evolução psicológica da criança. Lisboa: Edições. 70, 1968.

Enviado: Setembro, 2019.

Aprovado: Novembro, 2019. 